\title{
Drbem Analysis of Combined Wave Refraction and Diffraction in the Oresence of Current
}

\author{
Sung-Shan Hsiao \\ Associate Professor, Department of Harbor and River Engineering, National Taiwan Ocean University, 2 Pei-Ning Rd., \\ Keelung, Taiwan \\ Ming-Chung Lin \\ Professor, Department of Naval Architecture and Ocean Engineering, National Taiwan University, 73 Chow-Shan Rd., \\ Taipei, Taiwan \\ Nien-Chia Hu \\ Master, Department of Naval Architecture and Ocean Engineering, National Taiwan University, 73 Chow-Shan Rd., \\ Taipei, Taiwan
}

Follow this and additional works at: https://jmstt.ntou.edu.tw/journal

Part of the Civil and Environmental Engineering Commons

\section{Recommended Citation}

Hsiao, Sung-Shan; Lin, Ming-Chung; and Hu, Nien-Chia (2002) "Drbem Analysis of Combined Wave Refraction and Diffraction in the Oresence of Current," Journal of Marine Science and Technology. Vol. 10: Iss. 1, Article 8.

DOI: $10.51400 / 2709-6998.2301$

Available at: https://jmstt.ntou.edu.tw/journal/vol10/iss1/8

This Research Article is brought to you for free and open access by Journal of Marine Science and Technology. It has been accepted for inclusion in Journal of Marine Science and Technology by an authorized editor of Journal of Marine Science and Technology. 


\title{
DRBEM ANALYSIS OF COMBINED WAVE REFRACTION AND DIFFRACTION IN THE PRESENCE OF CURRENT
}

\author{
Sung-Shan Hsiao*, Ming-Chung Lin**, and Nien-Chia $\mathrm{Hu}^{* * * *}$
}

Key words: Wave refraction-diffraction, currents, DRBEM.

\begin{abstract}
A more effective numerical model using the dual reciprocity boundary element method (DRBEM) is presented to study the combined effects of wave refraction- diffraction and currents. The mildslope equation with current effects is reformulated to an inhomogeneous Helmholtz equation. Applying the conventional boundary element method to this inhomogeneous equation, the inhomogeneous part will result in a domain integral which makes the computation complicated and messy. To improve this drawback, the DRBEM is adopted to transform the domain integral to boundary integral. In order to verify the validity of this model, the relative amplitudes around a circular island without current effects were performed, and compared with analytical solutions of Homma (1950). The agreement is fairly satisfactory. The combined effects of wave refractiondiffraction and currents around a circular island over a variable water depth were calculated by this model. The results show that the model has a great potential to be used for solving the problem of combined wave refraction-diffraction and currents.
\end{abstract}

\section{INTRODUCTION}

The study of the combined effects of wave refraction-diffraction and currents becomes an important topic on ocean engineering nowadays. It has drawn attention of researchers to do the related investigation. Homma (1950) used the shallow water equation to investigate wave refraction and diffraction around a circular island. Berkhoff (1972), and later Vanstano and Reid (1975) derived the well-known mild-slope equation to describe wave refraction and diffraction. Booij (1981), Liu (1983) and Kirby (1984) extended the mild slope equation to include the effects of current. Based on the equation derived by Kirby (1984), a model using finite/ boundary element method was proposed by Lin et al.

Paper Received Sep. 27, 2001. Author for Correspondence: Sung-Shan Hsiao. *Associate Professor, Department of Harbor and River Engineering, National Taiwan Ocean University, 2 Pei-Ning Rd., Keelung, Taiwan

**Professor, Department of Naval Architecture and Ocean Engineering, National Taiwan University, 73 Chow-Shan Rd., Taipei, Taiwan

***Master, Department of Naval Architecture and Ocean Engineering, National Taiwan University, 73 Chow-Shan Rd., Taipei, Taiwan
(1994) to study the effects of wave refraction-diffraction together with a current. The model needs to place with a large number of finite elements in a variable seabed domain. Thus, the computer storage and time are formidable.

Zhu (1993a), Zhu and Zhang (1995) developed a numerical procedure using the DRBEM, which was first proposed by Nardini and Brebbia (1982), to study the combined refraction and diffraction of water waves propagating around islands or solid offshore structures over a variable seabed. More recently, Hsiao et al. (1997) adopted the DRBEM to improve the numerical model, which combined perturbation and boundary element method proposed by Rangogni (1988) for wave refraction and diffraction problems. The results of them show that a considerable improvement in terms of numerical efficiency has been achieved with the adoption of the DRBEM. Therefore, the DRBEM is used in this study in order to provide a more effective numerical model dealing with the combined effects of wave refraction-diffraction and currents.

\section{MATHEMATICAL FORMULATION}

As shown in Fig. 1, the domain of interest is divided into two regions: a bounded region $D_{1}$ with a variable water depth, and a semi-unbounded region $D_{0}$ having a constant water depth. While in the first region, current together with a large obstacle are present. $\alpha$ is the circular angle measured clockwise from positive $x$ axis with radius $R$. In the latter, it is assumed that effects of currents are negligible. The mild-slope equation derived by Booij (1981), Liu (1983) and Kirby (1984), describes the effects of wave refraction-diffraction in the presence of uniform currents:

$$
\frac{D^{2} \Phi}{D t^{2}}-\nabla \cdot\left(C C_{g} \nabla \Phi\right)+\left(\sigma^{2}-k^{2} C C_{g}\right) \Phi=0
$$

where $\frac{D^{2}}{D t^{2}}=\left(\frac{\partial}{\partial t}+\vec{U} \cdot \nabla\right)\left(\frac{\partial}{\partial t}+\vec{U} \cdot \nabla\right)$

Here, $\vec{U}$ is the current velocity, $\nabla$ represents a horizontal gradient operator, $\Phi$ is the surface velocity 


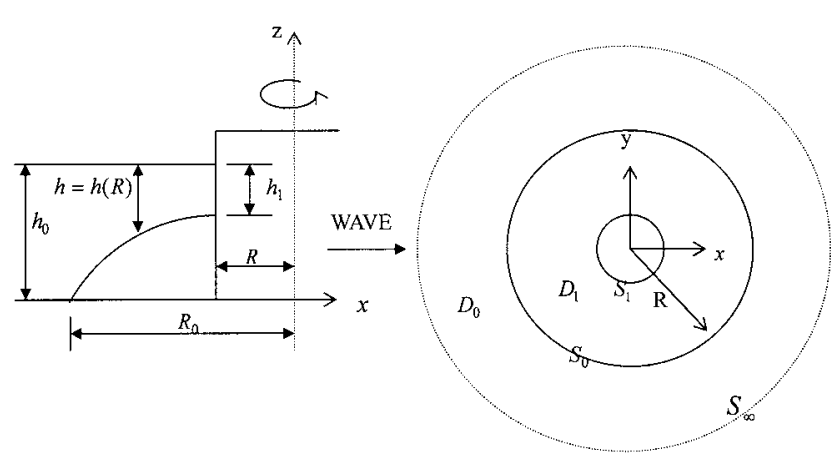

Fig. 1. Definition sketch of computational domain.

potential of the linearized wave motion, $h$ is water depth, $\sigma$ is the relative frequency, and $k$ is the wave number. $C$ and $C_{g}$ are respectively the local phase and group velocities calculated from the frequency $\sigma$ and the wave number $k$. For monochromatic wave with absolute frequency $\omega$ one has

$$
\Phi=\phi e^{-i \omega t}
$$

Substituting Eq. (2) into Eq. (1) and neglected the convective term, one can obtain

$$
\begin{aligned}
\nabla^{2} \phi+k_{0}^{2} \phi & =\left[\left(k_{0}^{2}-k^{2}\right)+\frac{1}{C C_{g}}\left(\sigma^{2}-\omega^{2}\right)\right] \phi \\
& -\frac{1}{C C_{g}}\left(\nabla C C_{g}+2 i \omega \vec{U}\right) \cdot \nabla \phi
\end{aligned}
$$

Where $k_{0}$ is the wave number in domain $D_{0}, \omega$ is the absolute frequency, $i=\sqrt{-1}$ is the imaginary constant, $\omega$ and $\sigma$ are related by Doppler's relation:

$$
\omega=\sigma+\vec{k} \cdot \vec{U}
$$

For waves propagating in the region $D_{0}$, without current interfering, Eq. (3) is then reduced to the Helmholtz equation

$$
\nabla^{2} \phi_{0}+k_{0}^{2} \phi_{0}=0
$$

Assuming that the velocity potential $\phi_{0}$, in the region $D_{0}$, can be expressed as a linear combination of the incident and scattered wave potential, i.e. $\phi_{0}=\phi^{i}+$ $\phi^{s}$. Substituting the expression of $\phi_{0}$ into Eq. (5), the governing equation for the scattered wave potential in region $D_{0}$ can be obtained.

$$
\nabla^{2} \phi^{s}+k_{0}^{2} \phi^{s}=0
$$

In the bounded region $D_{1}$ with variable water depth, the wave-current field around the obstacle is governed by Eq. (3), which is expressed as follows:

$$
\begin{aligned}
\nabla^{2} \phi_{1}+k_{0}^{2} \phi_{1}= & {\left[\left(k_{0}^{2}-k^{2}\right)+\frac{1}{C C_{g}}\left(\sigma^{2}-\omega^{2}\right)\right] \phi_{1} } \\
& -\frac{1}{C C_{g}}\left(\nabla C C_{g}+2 i \omega \vec{U}\right) \cdot \nabla \phi_{1}
\end{aligned}
$$

where, $\phi_{1}$ denotes the velocity potential in region $D_{1}$.

The boundary conditions for the computational domain are now specified as follows:

1. The boundary condition on the surface of the obstacle $S_{1}$ is given by

$$
\frac{\partial \phi_{1}}{\partial n}=0
$$

2. In the semi-unbounded region, the velocity potential of the scattered wave $\phi^{s}$ must satisfy the Sommerfeld radiation condition

$$
\lim _{r \rightarrow \infty} \sqrt{r}\left(\frac{\partial}{\partial r}-i k_{0}\right) \phi^{s}=0
$$

where $r=\sqrt{x^{2}+y^{2}}$.

3. For the boundary between bounded and semi-unbounded region, conservations of mass and energy flux of the fluid lead to the requirements that

$$
\left\{\begin{array}{l}
\phi_{1}=\phi_{0}=\phi^{s}+\phi^{i} \\
\frac{\partial \phi_{1}}{\partial n}=-\frac{\partial \phi_{0}}{\partial n^{\prime}}=-\left(\frac{\partial \phi^{s}}{\partial n^{\prime}}+\frac{\partial \phi^{i}}{\partial n^{\prime}}\right)
\end{array} \text { on } S_{0}\right.
$$

Here $n$ and $n^{\prime}$ are the outer normal derivatives for the bounded and semi-unbounded regions, respectively.

\section{DESCRIPTION OF THE MODEL}

In the semi-unbounded region $D_{0}$, the governing equation for the scattered wave potential is the Helmholtz equation as shown in Eq. (6). If the weighting function $\phi^{*}$ is chosen as $\phi^{*}=-\frac{i}{4} H_{0}^{(1)}(k r)$, where $H_{0}^{(1)}$ is the Hankel function of the first kind with zero order, and $r$ is the distance between a source point and a field point. By applying the Green's second identity, and substituting the boundary condition on $S_{\infty}$ (Eq. (9)) into Eq. (6) lead to the following boundary integral equation :

$$
C_{0 i} \phi_{i}^{s}=\int_{S_{1}}\left(\phi_{s} \frac{\partial \phi^{*}}{\partial n^{\prime}}-\phi^{*} \frac{\partial \phi^{s}}{\partial n^{\prime}}\right) d s, \quad C_{0 i}= \begin{cases}1 & \text { in } D_{0} \\ \frac{1}{2} & \text { on } S_{0}\end{cases}
$$

In the bounded region, the governing equation for 
the wave-current coexisting field, Eq. (7) is an inhomogeneous Helmholtz equation. Multiplying both side of Eq. (7) by the same weighting function as that in Eq. (11) and applying Green's theorem again, one can obtain

$$
\begin{aligned}
& C_{1 i} \phi_{1 i}-\int_{S} \phi_{1} \frac{\partial \phi^{*}}{\partial n} d s+\int_{S} \phi^{*} \frac{\partial \phi_{1}}{\partial n} d s=\iint_{D_{1}} \phi^{*} b d A, \\
& C_{1 i}= \begin{cases}1 & \text { in } D_{1} \\
\frac{1}{2} & \text { on } S_{1}\end{cases}
\end{aligned}
$$

where $S=S_{1}+S_{0}$ is the boundary of region $D_{1}$, and $b$ denotes the inhomogeneous part, i.e., the right hand side of Eq. (7).

Once the boundary conditions, Eq. (10), on the boundary $S_{0}$ are imposed, the system of integral equations of Eq. (11) and Eq. (12) can be simplified combined as:

$$
\begin{aligned}
\left(C_{1 i}\right. & \left.+C_{0 i}\right) \phi_{1 i}-\int_{S_{1}}\left(\phi_{1} \frac{\partial \phi^{*}}{\partial n}-\phi^{*} \frac{\partial \phi_{1}}{\partial n}\right) d s \\
-\int_{S_{0}}\left(\phi^{i} \frac{\partial \phi^{*}}{\partial n}-\phi^{*} \frac{\partial \phi^{i}}{\partial n}\right) d s & =C_{0 i} \phi^{i}+\iint_{D_{1}} \phi^{*} b d A
\end{aligned}
$$

The domain integral on the right hand side of Eq. (13) is now dealt with by DRBEM. Based on the theory of DRBEM (Partridge et $a l, 1992$ ), the function $b$ can be approximated as:

$$
b=\sum_{k=1}^{N+L} \alpha_{k} f_{k}
$$

where $N$ is the number of nodes on the boundary, $L$ is the number of internal points, $\alpha_{k}$ are unknown coefficients to be determined by the collocation method, and $f_{k}$ are expansion functions, which can be expressed by the distance function $r_{k}$ from the source point to a specified point and can be chosen as $f_{k}=1+r_{k}$. If there exists a function $\hat{\phi}_{k}$ that satisfies:

$$
\nabla^{2} \hat{\phi}_{k}+k_{0}^{2} \hat{\phi}_{k}=f_{k}
$$

where the particular solutions $\hat{\phi}_{k}$ for Eq. (15) can be found in Zhu(1993b), then substituting Eqs. (14) and (15) into Eq. (13), we have

$$
\begin{aligned}
\left(C_{1 i}\right. & \left.+C_{0 i}\right) \phi_{1 i}-\int_{S_{1}}\left(\phi_{1} \frac{\partial \phi^{*}}{\partial n}-\phi^{*} \frac{\partial \phi_{1}}{\partial n}\right) d s \\
& -\int_{S_{0}}\left(\phi^{i} \frac{\partial \phi^{*}}{\partial n}-\phi^{*} \frac{\partial \phi^{i}}{\partial n}\right) d s \\
& =C_{0 i} \phi^{i}+\sum_{k=1}^{N+L} \alpha_{k}\left[C_{2 i} \hat{\phi}_{i k}-\int_{S} \hat{\phi}_{k} \frac{\partial \phi^{*}}{\partial n} d s\right. \\
& \left.+\int_{S} \phi^{*} \frac{\partial \hat{\phi}_{k}}{\partial n} d s\right]
\end{aligned}
$$

where the coefficient $C_{2 i}$ equals 1 if the point lies inside the bounded region $D_{1}, 1 / 2$ if it lies on the smooth boundary $S$, and equals to 0 if it lies outside the bounded region $D_{1}$. After discretizing the boundaries $S_{0}$ and $S_{1}$ with constant element and applying the standard DRBEM procedures, a linear system of algebraic equations is obtained as

$$
\left(\mathbf{H}-\lambda^{\prime} \mathbf{S}+\lambda^{\prime \prime} \mathbf{R}\right) \phi=\mathbf{G} \mathbf{q}-\mathbf{H}^{\prime} \phi^{i}+\mathbf{G}^{\prime} \mathbf{q}^{i}
$$

where

$$
\begin{aligned}
& \lambda^{\prime}=\left(k_{0}^{2}-k^{2}\right)+\frac{1}{C C_{g}}\left(\sigma^{2}-\omega^{2}\right) \\
& \lambda^{\prime \prime}=-\frac{1}{C C_{g}}\left(\nabla C C_{g}+2 i \omega \vec{U}\right) \\
& \mathbf{S}=(\mathbf{H} \hat{\phi}-\mathbf{G} \hat{\mathbf{q}}) f^{-1} \\
& \mathbf{R}=\mathbf{S} \frac{\partial f}{\partial x} f^{-1}
\end{aligned}
$$

$\phi$ is an $(N+L) \times 1$ vector, the first $N$ entries of which are the nodal values of $\phi_{1}$ defined on $S$, and the last $L$ entries of which are the nodal values of $\phi_{1}$ defined on the internal points; $\mathbf{q}$ is an $(N+L) \times 1$ vector, the $N$ entries of which are the normal derivatives of $\phi_{1}$, defined on $S . \phi^{i}, \mathbf{q}^{i}$ and $\hat{\phi}, \hat{\mathbf{q}}$ are the vectors of the same dimension as $\phi$ and $\mathbf{q}$ respectively. $\mathbf{H}, \mathbf{G}, \mathbf{H}^{\prime}$ and $\mathbf{G}^{\prime}$ are of the usual meaning, which can be worked out with standard BEM procedure. While the boundary conditions on $S_{1}$, Eq. (8), are imposed, Eq. (17) can be solved with the inversion of an $(N+L)$ by $(N+L)$ complex matrix.

\section{MODEL VERIFICATIONS}

In this study, Homma's (1950) analytical examples for wave refraction-diffraction around a circular island over a paraboloidal shoal (as shown in Fig. 1) was performed to verify the validity of the present model. Three difference geometries (A, B and C) are considered as listed in Table 1.

The wave period $T=240,480,720$ and 1440 seconds are chosen as the conditions of the incident waves. The relative amplitude around a circular island on a paraboloidal shoal without current effects (i.e. $U=$ $0)$ was firstly calculated. Fig. 2 shows the numerical results of three different geometries together with the analytical solutions of Homma (1950) for the incident wave period $T=480 \mathrm{sec}$. Furthermore, a comparison between the present numerical results and the analytical results of Homma (1950) with the incident wave period $T=240,480,720,1440$ seconds (see Fig. 3) was made. The agreement is fairly satisfactory. 
Table 1. Conditions used for the numerical calculation

\begin{tabular}{cccccc}
\hline & $R_{1}(\mathrm{~m})$ & $R_{0}(\mathrm{~m})$ & $h_{1}(\mathrm{~m})$ & $h_{0}(\mathrm{~m})$ & $h_{0} / h_{1}$ \\
\hline Geometry A & & $11,547.00$ & $3,000.00$ & & 1.33 \\
Geometry B & $10,000.00$ & $17,329.18$ & $1,333.33$ & $4,000.00$ & 3.00 \\
Geometry C & & $20,000.00$ & $1,000.00$ & & 4.00 \\
\hline
\end{tabular}

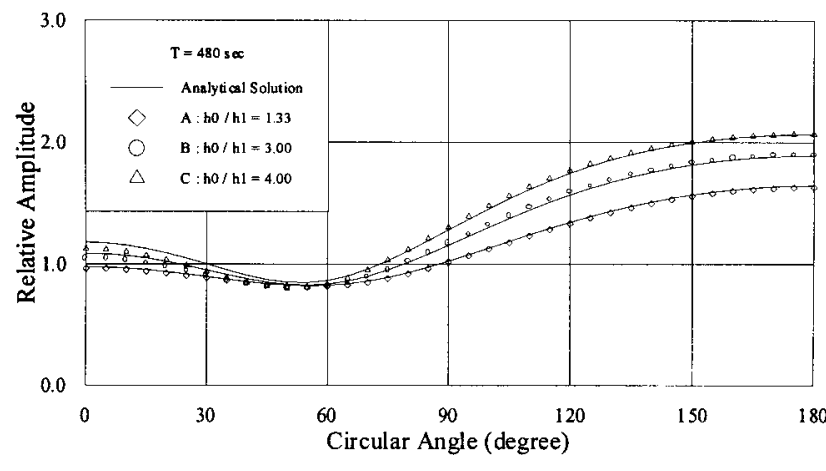

Fig. 2. Comparison between the numerical solutions and the analytical solutions for relative amplitudes around the island with wave period $T=480 \mathrm{sec}$ (geometry A, B and C).

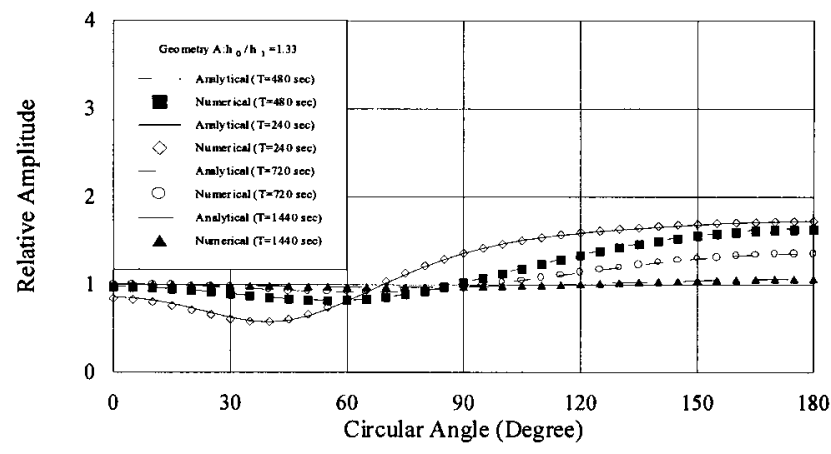

Fig. 3. Comparison between the numerical solutions and the analytical solutions for relative amplitudes around the island (geometry A) with different wave periods.

\section{NUMERICAL EXAMPLES}

Variations of the relative amplitude around a circular island under the effects of current were calculated for geometries $A$ and $B$. The current velocities $U$ are 10 $\mathrm{m} / \mathrm{sec}$ and $20 \mathrm{~m} / \mathrm{sec}$, the intersection angle $(\theta)$ between wave and current varies from $0^{\circ}, 90^{\circ}$ to $180^{\circ}$. To facilitate data analyzing, the whole domain is divided into four regions, $A, B, C$, and $D$, as shown in Fig. 4. The regions are separated by two lines: one is drawn along the incident $(\mathrm{CI})$ and outgoing (CD) current rays, and the other is perpendicular to it, both passing through the center of the circular island. Regions A and B are called

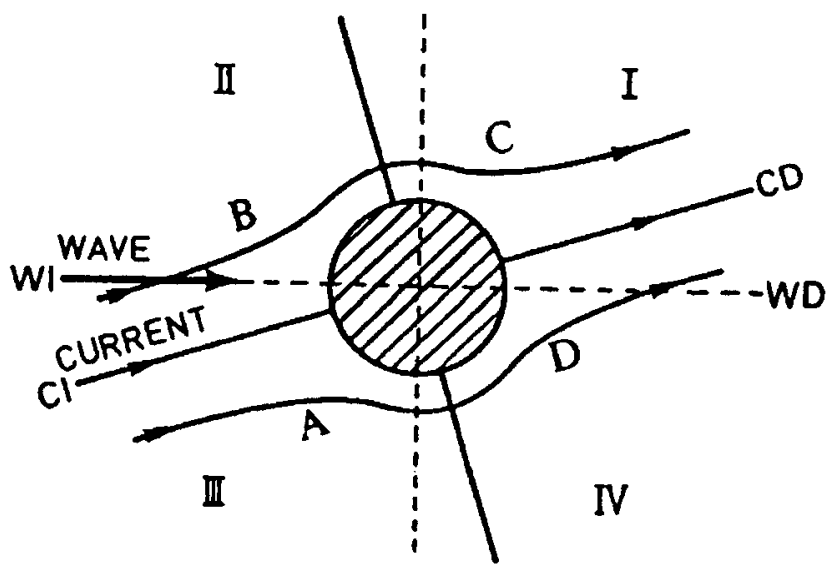

Fig. 4. Definition sketch of regions used for data analysis.

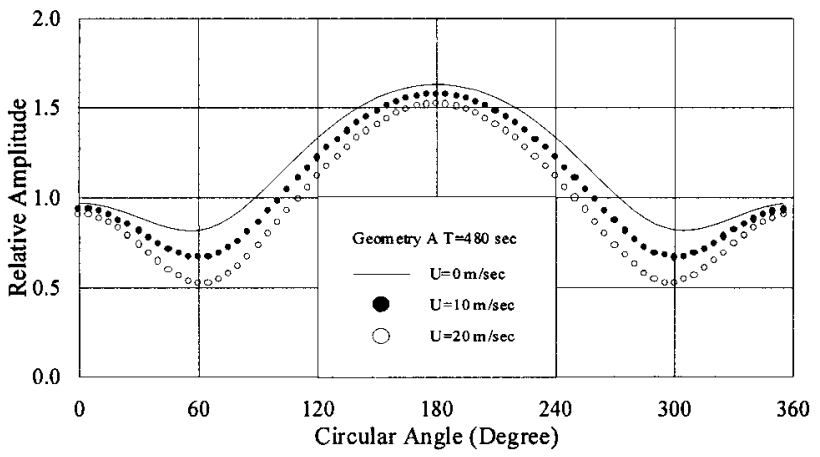

Fig. 5. Relative amplitude around a circular island (geometry A) for the intersection angle $\theta=0^{\circ}$

the inflow side, where angles between the diffracted wave ray and current ray are smaller than $90^{\circ}$. Regions $C$ and $D$ are called outflow side. Four quadrants can be similarly defined based on the direction of the incident waves (WI and WD). Quadrants I and IV will be called the downwave regions, while the other quadrants are the upwave regions.

Figures. 5 and 6 show the results of the relative amplitude distribution around the circular island of geometries $A$ and $B$. The waves-current intersection angle is zero which means that waves are traveling along with the current (i.e., parallel to the positive $x$ axis ). Three curves of different current $(U=0,10$, and 


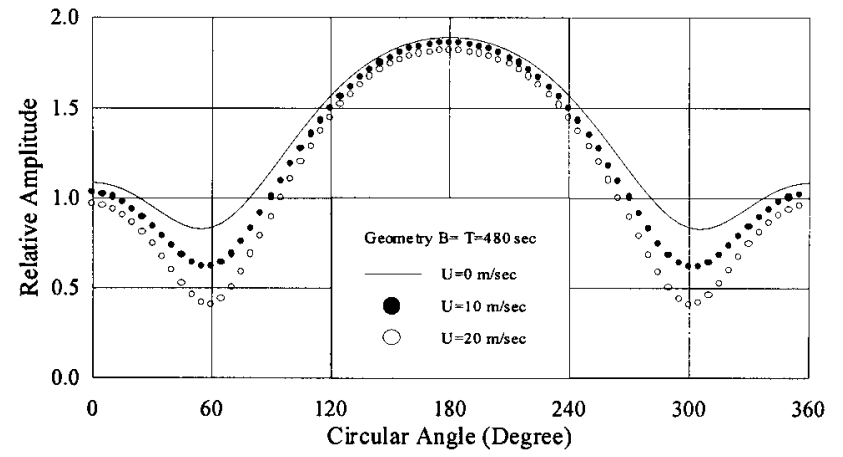

Fig. 6. Relative amplitude around a circular island (geometry B) for the intersection angle $\theta=0^{\circ}$.

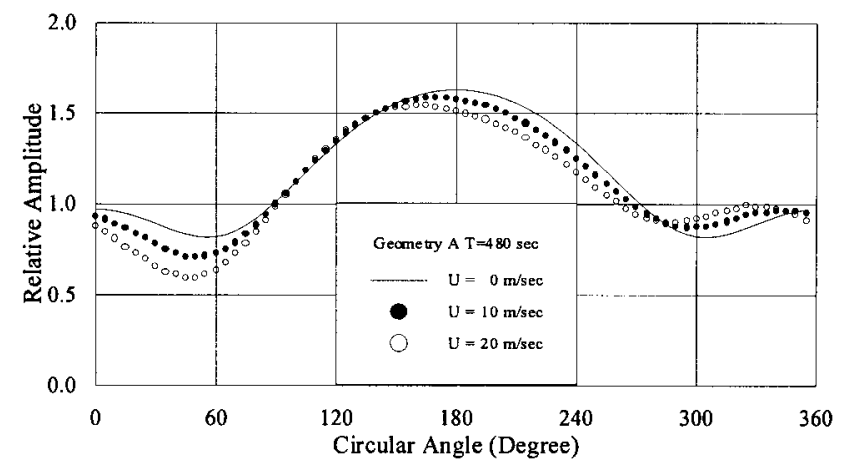

Fig. 7. Relative amplitude around a circular island (geometry A) for the intersection angle $\theta=90^{\circ}$.

$20 \mathrm{~m} / \mathrm{sec}$, respectively) are presented for the comparison. All curves show that the largest relative amplitude occurs at the so-called stagnation point which is directly attacked by the current ( $\alpha=180^{\circ}$ in the figures). The amplitude decreases symmetrically on both sides. The smallest amplitude occurs around $\alpha=60^{\circ}$ and (i.e., $\pm 60^{\circ}$ referred to the wave direction at the downwave side). Two figures also show that the relative amplitudes will decrease as $U$ increases. Such phenomenon is more pronounced for the case of geometry $B$ in Fig. 6 . The phenomenon is because of the waves propagating on a favorable current the wave height becomes smaller than when no current is present, and also decreases even when the current magnitude increases.

Figures 7 and 8 show the results of the wavecurrent intersection angle $\theta$ is equal to $90^{\circ}$ which mean that current is coming from the positive to the negative direction of the $y$-axis, while waves are traveling along the $x$-axis from left to right. Three curves of different current celerity ( $U=0,10$, and $20 \mathrm{~m} / \mathrm{sec}$, respectively) are presented for the comparison. The curves of nonzero current celerity lose their characteristics of symmetry referred neither to the wave direction (WI-WD

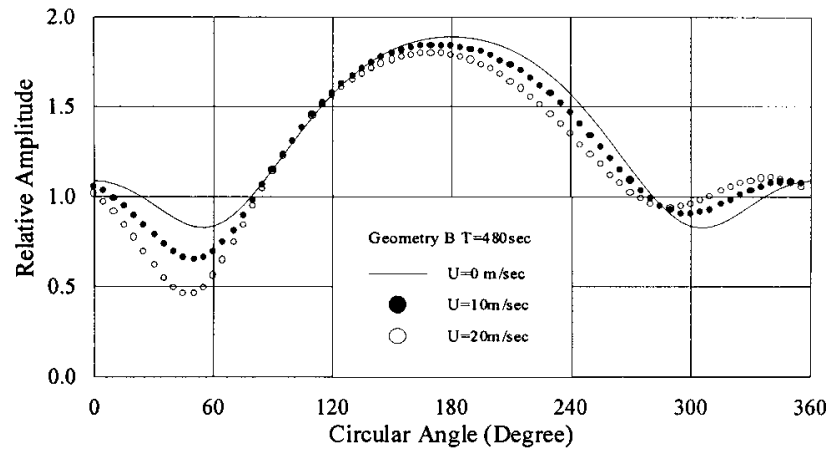

Fig. 8. Relative amplitude around a circular island (geometry B) for the intersection angle $\theta=90^{\circ}$.

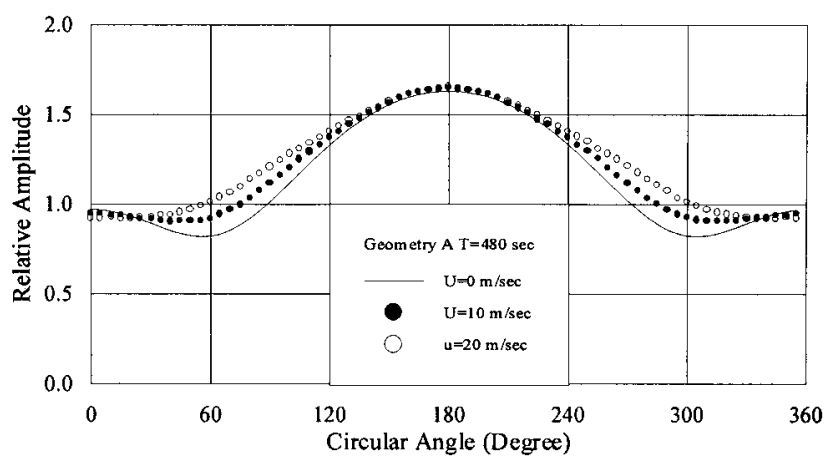

Fig. 9. Relative amplitude around a circular island (geometry A) for the intersection angle $\theta=180^{\circ}$.

line in Fig. 4) nor to the current direction (CI-CD line in Fig. 4). Due to the combined effect of waves and current, the largest relative amplitude didn't occur at the stagnation point ( $\alpha=90^{\circ}$ in the figures). However, we can also observe that as the celerity of current is increased the location of the largest amplitude approached to the current direction. Such phenomenon offers the information that wave conditions around a circular island are affected by the interaction effect between incident waves and current. The dominant effect can be affected by the celerity of the current. In the downwave region, the relative amplitude in the outflow side $\left(\alpha=270^{\circ}-360^{\circ}\right)$ is larger than that of zerocurrent case, and is increased with the increasing current celerity. While such phenomenon does not occur in the inflow side. More obvious evidence can be found in the case of geometry $B$ (Fig. 8).

Figs. 9 and 10 show the results of the wavecurrent intersection angle $\theta$ is equal to which means that current is coming from the opposite direction to the incident wave direction. That is, the waves are coming from left to right along the $x$-axis, while the current is traveling from right to left. Three curves of different 


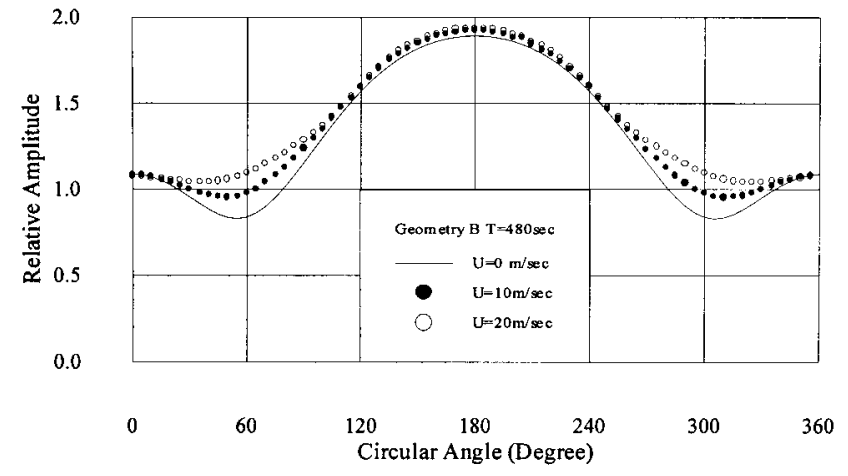

Fig. 10. Relative amplitude around a circular island (geometry B) for the intersection angle $\theta=180^{\circ}$.

celerity ( $U=0,10$, and $20 \mathrm{~m} / \mathrm{sec}$, respectively) are also shown in Figs. 9 and 10, as shown in Figs. 5 and 6 the characteristics of symmetry are coming back again, and the largest relative amplitude occurs at the so-called stagnation point in all curves ( $\alpha=180^{\circ}$ in the figures). The amplitude is still decreased symmetrically on both sides, and the smallest amplitude occurs around $\alpha=60^{\circ}$ and $300^{\circ}$ (i.e., $\pm 60^{\circ}$ referred to the wave direction at the downwave side). However, difference occurs between Figs. 5 and 6 and Figs. 9 and 10 that the relative amplitude is increased as $U$ increases. Such phenomenon is more obviously shown in Fig. 10 for the case of geometry $B$. The phenomenon is due to the waves propagating on an adverse current the wave height becomes larger than when no current is present, and also increases even when the current magnitude decreases.

From the discussion above, it demonstrates that, (a) with waves propagating on a favorable current, the relative amplitude becomes smaller as compared with the case of absence of current, and also decreases with increasing current velocity, and (b) for the waves propagating on an adverse current, an opposite trend is found. (c) The trend of the relative amplitude decreases (increases) with increasing current velocity is more pronounced for geometry $B$, which has a larger depth ratio $\left(h_{0} / h\right)$ than geometry $A$.

\section{CONCLUSION}

A more effective numerical model for the combined effects of wave refraction- diffraction and currents around a circular island over a seabed with variable water depth has been developed by employing the dual reciprocity boundary element method (DRBEM). The cases with no current effects were firstly calculated, and compared with the analytical solutions of Homma (1950). The agreement is fairly satisfactory. Using the proposed model, the combined effects of refraction- diffraction and currents around a circular island were further calculated. The numerical results show qualitative agreement. Therefore, the DRBEM model proposed here has its adaptability to deal with the interaction between wave-current and large structures.

\section{REFERENCES}

1. Berkhoff, J.C.W., "Computation of Combined Refraction-Diffraction," 13th Int. Conf. Coastal Engng., Vancouver, pp. 471-490 (1972).

2. Booij, N., "Gravity Waves on Water with Non-uniform Depth and Currents", Communication on Hydraulics, Rep. No. 81-1, Dept. of Civil Eng., Delft Univ. of Technology, The Netherland (1981).

3. Homma, S., "On the Behavior of Seismic Sea Waves around Circular Island," Geophys. Mag., 21, pp. 231233 (1950).

4. Hsiao, S.S., Wu, J.H. and Chiu, Y.F., "A PerturbationDRBEM Model for Wave Refraction-Diffraction", Proc. 7th Int. Offshore and Polar Eng. Conference, Honolulu, USA, pp. 308-312 (1997).

5. Kirby, J.T., “A Note on Linear Surface Wave-Current Interaction over Slowly Varying Topography", J. Geophys. Res., Vol. 89, No. C1, pp. $745-747$ (1984).

6. Lin, M.C., Hsiao, S.S. and Hsu, Y.C., "Wave RefractionDiffraction in the Presence of a Current," China Ocean Eng., Vol. 8, No. 3, pp. 307-320 (1994).

7. Liu, P.L.-F., "Wave-Current Interaction on a Slowly Varying Topography”, J. Geophys. Res., Vol. 88, pp. 4421-4426 (1983).

8. Nardini, D and Brebbia, C.A., "A New Approach to Free Vibration Analysis Using Boundary Elements", Boundary Element Methods in Engineering, ed. C. A. Brebbia, Springer-Verlag, Berlin, New York (1982).

9. Partridge, P.W., Brebbia, C.A., and Wrobel, L.C., "The Dual Reciprocity Boundary Element Method", Computational Mechanics Publications, New York (1992).

10. Rangogni, R., "A Simple Procedure to Solve the MildSlope Equation using BEM and Perturbation TechniquePart I', Boundary Elements X, Vol. 1, ed. C. A. Brebbia, Computational Mechanics Publications, SpringerVerlag, Berlin, pp. 331-343 (1988).

11. Vanstano, A.C. and Reid, R.O., "Tsunami Response for Island: Verification of a Numerical Procedure", J. Mar. Res., Vol. 25, pp.129-139 (1967).

12. Zhu, S., "A New DRBEM Model for Wave Refraction and Diffraction", Eng. Analysis with Boundary Elements, Vol. 12, pp. 261-274 (1993a).

13. Zhu, S, "Particular Solutions Associated with Helmholtz Operator Used in DRBEM", BE Abstracts, Vol. 4, No. 6, pp. 231-233 (1993b).

14. Zhu, S. and Zhang, Y., "Combined Refraction and Diffraction of Short Waves Using the Dual Reciprocity 
Boundary Element Method", Applied Ocean Res., Vol.

17, pp. 315-322 (1995).

\section{水流存在時波浪折繞射之雙互換邊 \\ 界元素法解析}

蕭松山

國立台灣海洋大學河海工程學系

林銘崇胡念嘉

國立台灣大學造船及海洋工程學系

摘 要

本文以含水流效應之緩坡方程式爲基礎, 應用 隻互換邊界元素法(DRBEM)解析波浪折繞射與水流 之共同效應。首先將含水流效應之緩坡方程式重新整 理爲非齊次之Helmholtz方程式, 再利用Green公式改 寫爲積分方程式, 但利用一般傳統邊界元素法解析 時, 將存在一領域積分項, 使得邊界元素法顯得繁雜 且不完美, 爲改善此一缺陷, 本文乃應用隻互換邊界 元素法之技巧, 以節省大量之數值計算時間。本文以 海啸波作用於緩變地形上之圆島爲計算例, 在無水流 存在時之計算結果, 與前人研究之解析解相當吻合, 隨即加入水流效應計算波浪折繞射與水流之共同效 應, 其計算結果在定性上相當合理, 顯示本文提出之 數值計算模式應能有效解析有關波浪折繞射與水流之 共同效應問題。 